\title{
INTEGRATED OBSERVATION OF AEROSOL PLUMES TRANSPORT AND IMPACTS ON THE AIR QUALITY REMOTE SENSING IN THE NORTHEAST U.S.
}

\author{
Yonghua Wu*, Chowdhury Nazmi, Zaw Han, Cuiya Li, Barry Gross, Fred Moshary \\ Optical Remote Sensing Lab and NOAA-CREST, City College of New York (CCNY), NY 10031, USA. \\ *Email: yhwu@ccny.cuny.edu
}

\begin{abstract}
In this paper, we present a cluster analysis of plume transport paths to New York City (NYC, $40.821^{\circ} \mathrm{N}, 73.949^{\circ} \mathrm{W}$ ) for the 8 -year period during 2006-2013. We also show cases of such aloft aerosol plumes intrusion and mixing into the boundary layer (PBL) and the impact on local air quality. Range-resolved monthly occurrence frequency and modification of local aerosol optical properties are presented. The NOAA-HYSPLIT cluster analysis indicates 6 main transport paths; and the optical properties (optical depth-AOD, Angstrom exponent-AE and single scatter albedoSSA) of aerosol for each cluster are characterized. We further illustrate the impact of these aloft plumes on the satellite MODIS estimate of ground $\mathrm{PM}_{2.5}$ levels and observe that when the aloft plumes-layer AODs are filtered out using lidar, the correlation of MODIS AOD-PM ${ }_{2.5}$ can be much improved.
\end{abstract}

\section{INTRODUCTION}

Aloft aerosol plumes from both forest-fires and dust storms events are often transported over long distance, affecting both climate radiation and air quality on regional/continental scales $[1,2]$. They often result in significant contribution to the column aerosol optical depths (AOD) which can bias the estimate of $\mathrm{PM}_{2.5}$ from the satellite column observation $[3,4]$. The optical properties and timeheight statistics of these transported plumes can be characterized by long-term ground lidar observations. In this study, we present the climatology of aloft aerosol plumes using synergistic observations from a co-located multiwavelength lidar and AERONET-sunphotometer. The potential impacts on the local aerosol optical properties, air quality and the MODIS AOD-PM 2.5 correlation are analyzed.

\section{INSTRUMENTS AND METHODOLOGY}

At CCNY, a suite of ground-based remote sensing instruments are deployed on a building roof, near a standard surface air quality monitoring station deployed by the New York State Department of Environment Conservation for $\mathrm{PM}_{2.5}$ mass concentration, ozone and $\mathrm{CO}$ measurement. The instruments include a 3-wavelength elastic-Raman lidar, a ceilometer (Vaisala CL-31), an AERONET Cimel sun/sky radiometer, a multi-filter shadow band radiometer (YES MFR-7) and a microwave radiometer (Radiometrics MP-3000A). The lidar emits three wavelengths (355-, 532- and 1064-nm) with a flashlamp-pumped Nd: YAG laser at a repetition rate of $30 \mathrm{~Hz}$ (Spectra-physics QuantaRay PRO-320) [5]. Three elastic-scattering and two Raman-scattering returns by nitrogen and water vapor molecules excited by $355-\mathrm{nm}$ laser output are collected by a receiver telescope (Ø50$\mathrm{cm})$. The signals are acquired by LICEL transient recorders (TR40-160) and recorded with 1-min average. AERONET sun/sky radiometer provide column AOD, Angstrom exponent (AE), microphysical parameters (volume size distribution and refractive index, effective radius$\left.\mathrm{R}_{\mathrm{eff}}\right)$, and SSA [6].

The lidar is generally operated under the clear or partly cloudy sky at 10:00-18:00 local time, 3day/week. An aloft-aerosol-layer event is identified via the lidar imagery of range-corrected returns at 1064-nm, with the aerosol-layer above PBL, duration time $>3 \mathrm{hr}$ and geometric depth $\geq$ $300 \mathrm{~m}$. Due to general SNR limit of Ramanchannel in the daytime, we derive aerosol extinction profiles with the elastic returns by using SP-measured AOD to constrain lidar-ratio, and the resultant Angstrom exponent profile is derived to classify aerosol types in the plumes [7].

\section{OBSERVATIONS}

\subsection{A case of Canadian smoke plume transport}

A heavy smoke transport event was observed by the CCNY-lidar on Aug. 8, 2014. Figure 1 (a) 
shows the time-height cross section of the aerosol extinction coefficient, Angstrom exponent, constrained lidar-ratio and segmented AOD. Lidar data illustrate one dense aerosol plume layer at $4 \sim 8 \mathrm{~km}$ altitude with the corresponding Angstrom exponent of 1.6-2.0, which indicates that the plume is fine mode aerosol dominated. The column averaged lidar-ratios were then obtained with values of $71.7 \pm 3.5 \mathrm{sr}$ at $532-\mathrm{nm}$ and $39.8 \pm$ $4.9 \mathrm{sr}$ at 1064-nm, respectively. The column AOD measurements are mostly due to the aloft-aerosolplumes. The NOAA-HYSPLIT backward trajectory and NOAA-HMS (Hazard Map System) satellite analysis indicate that these plumes are transported from Canadian forest fire events, and traveled to the eastern US within 3-day by the high-level jets. This demonstrates the significant effect long range transport can have on local conditions and illustrates the value of multiwavelength techniques to identify the plume characteristics.
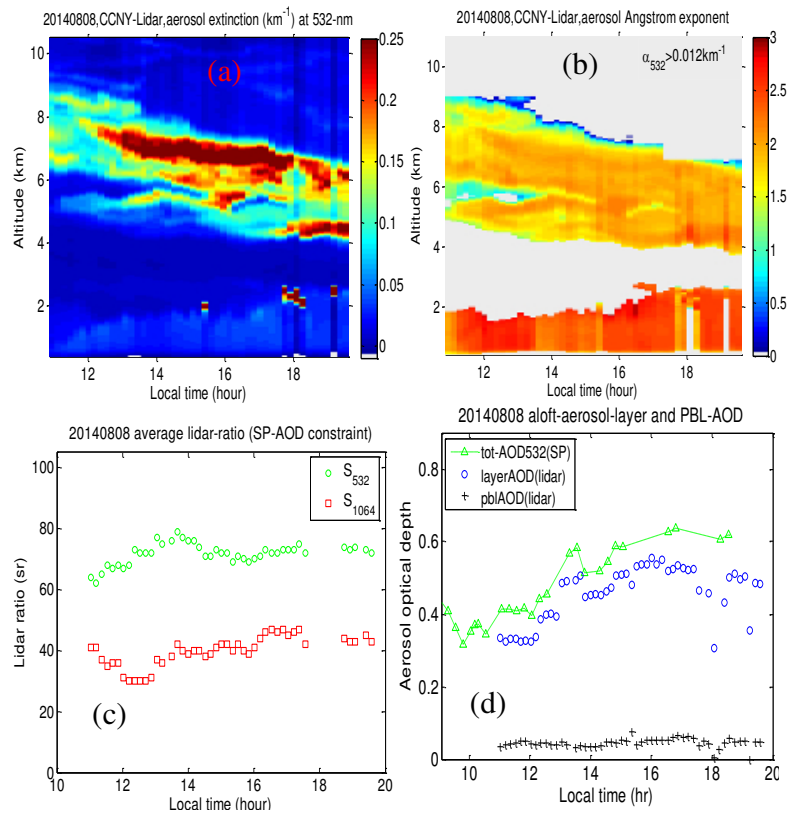

Fig.1. (a)-(d) Time-height cross section of aerosol extinction, Angstrom exponent at 532-1064-nm, lidar-ratio and aloft-layer AOD on Aug.8, 2014.

\subsection{Range-resolved aloft aerosol layer occurrence and modification of local aerosol optical properties}

Our routine lidar observations frequently detect aloft aerosol layers over NYC. Our long term datasets allow us to build climatology of aerosol plume transport and properties. The range- resolved monthly average occurrence of aloft aerosol layers is estimated from the identified aloft-plume days over the total days of lidar observation during 2006 - 2013. The result is given in Fig. 2a. Most episodes occur mainly from March to September, with higher altitude in spring and lower in summer, making the summer months most susceptible to smoke intrusions into the PBL. The monthly average of sunphotometer (SP) AOD and Angstrom exponent on the aloft-aerosol-plume days and clear days are compared in Fig.2b-c. Generally, significant enhancement of AOD occurs on the aloft-plume-days during April to September. Angstrom exponents become much lower in April on plumes days indicating more coarse-mode particles that might be associated with the Asian dust transport. In summer, on plumes days, the higher Angstrom exponents indicate fine-mode dominant particles that might be associated with the aged smoke transport, but they are only slightly lower than the ones on the clear day with the urban aerosols.
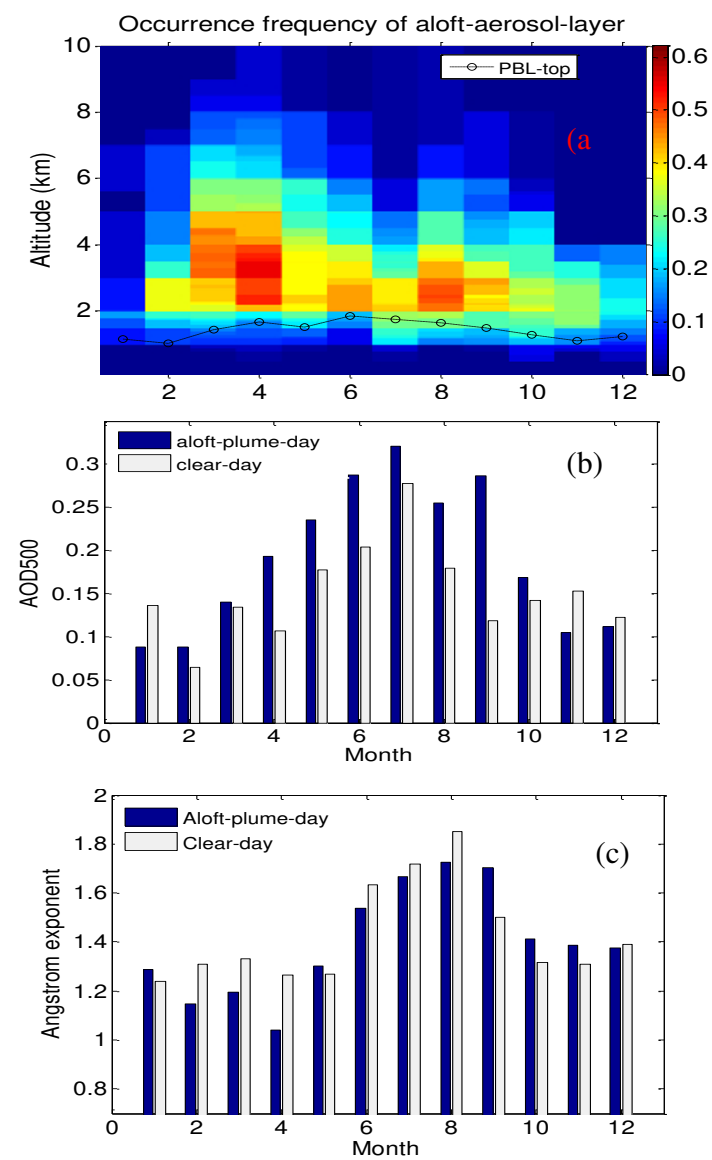

Fig.2 (a)-(c) Monthly occurrence of aloft-aerosolplume, column AOD, Angstrom exponent in NYC. 


\subsection{Cluster analysis of aerosol transport paths}

With the identified plumes events from the lidar images, the transport pathways of elevated aerosol plumes are classified with the cluster analysis of HYSPLIT-trajectories. A total of 6 clusters are determined from the total spatial variance (TSV) of 283 trajectories (ending points at 15:00 UTC, 4$\mathrm{km}$ altitude and duration of 72-hr long) as shown in Fig. 3a. The mean aerosol properties (AOD, AE, SSA and $\mathrm{R}_{\text {eff }}$ ) are analyzed for each cluster shown in Fig.3. Cluster-2 shows the air mass transported from the Great Lakes area (shortest range travel, $22 \%$ fraction), with aerosols that show both larger AOD and Angstrom exponent with SSA=0.91. This is possibly associated with the transport of industrial emissions. Cluster-6 (longest distance travel, 9\% fraction) shows the air mass transported from the Pacific Ocean via the northwest US; with aerosols that have smaller Angstrom exponent and large effective radius with the mean $\mathrm{SSA} \approx 0.95$. This is likely linked with the trans-Pacific Asian dust transport. Other clusters show similar optical properties of aerosols with the mean AOD of 0.2 and Angstrom exponent of 1.5, the smaller SSA and effective radius may indicate the transport of aged biomass burning aerosols.

\subsection{Impact on the local air quality}

The aloft-aerosol-plumes can be mixed down to the surface via the processes of PBL entrainment and/or air subsidence, thus potentially affecting the surface air quality. The mixing-down events can be visually identified from the time-height lidar imagery. In Fig. 4, the average surface $\mathrm{PM}_{2.5}$ concentration is compared for the days where aloft-plume mixing-down is observed to clear days or days where no-mixing is observed. It can be seen that the $\mathrm{PM}_{2.5}$ concentrations are clearly higher on the mixing-down days than for the other days. In particular, during 12:00-16:00 local time, the $\mathrm{PM}_{2.5}$ shows a dramatic increasing trend on the mixing-down days but is stable and low level on the clear days due to the PBL development during mid-day.

\subsection{Plume impact on MODIS-AOD/Surface $\mathbf{P M}_{2.5}$ correlation}

As shown in Fig.1, the lidar data can be used to study the effect of aloft plumes on potential correlation between the MODIS-AOD and surface
$\mathrm{PM}_{2.5}$. We compare their linear regression results before and after filtering out the aloft-plume-layer data in summer, for 2010 to 2013. As shown in Fig.5, when filtering out the aloft plume cases, a better linear correlation coefficient and a bigger slope are observed as well as a reduction of the DC offset which is indicative of removal of aloft contamination As expected, poor correlation is seen when only the smoke plume cases are studied. We observe similar effects in spring with the dust transport; the linear slope increases from 20.6 to 42.3 and the correlation coefficient is improved from 0.39 to 0.51 when filtering out the aloft-aerosol-plumes data (not shown here).
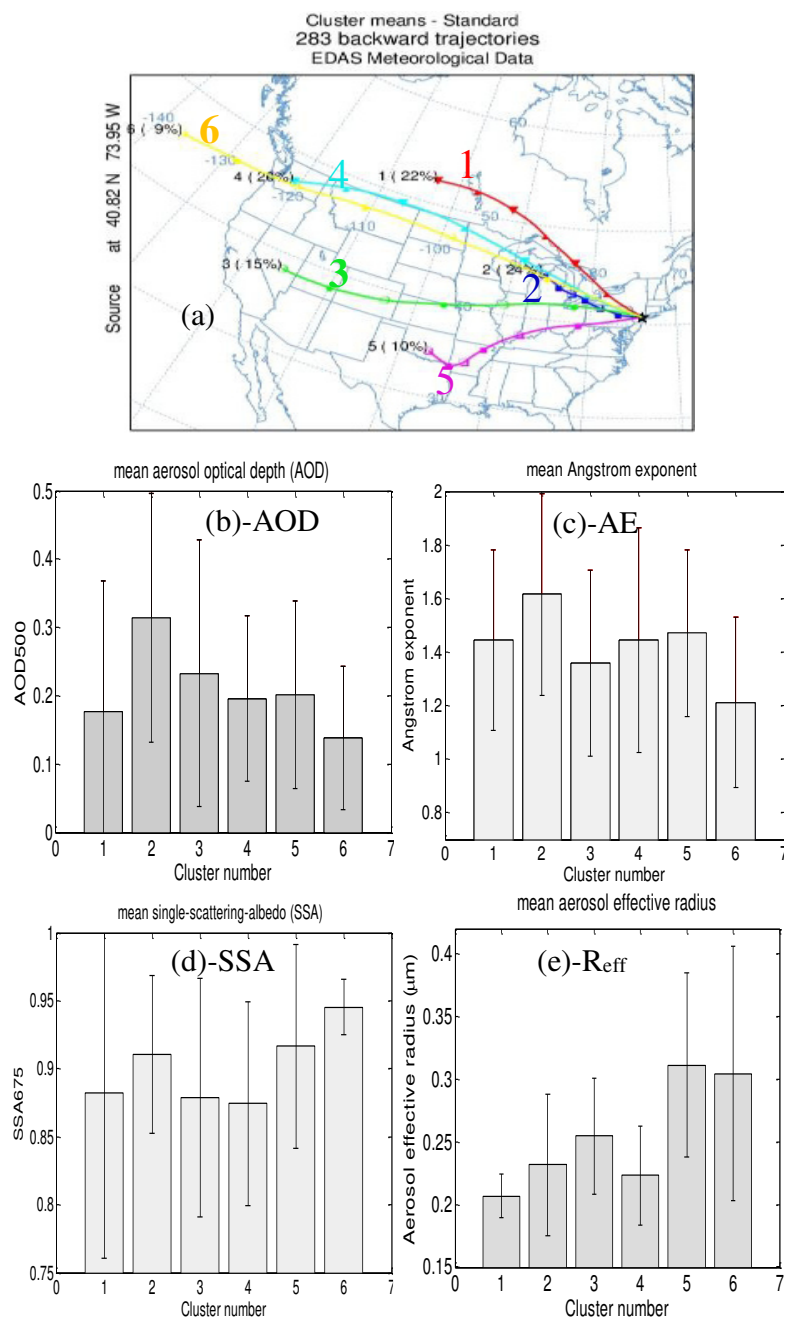

Fig.3. (a) Cluster analysis of aloft-aerosol-plume transport paths, (b) column average AOD, (c) Angstrom exponent, (d) single-scattering-albedo, and (e) effective radius for each cluster. 


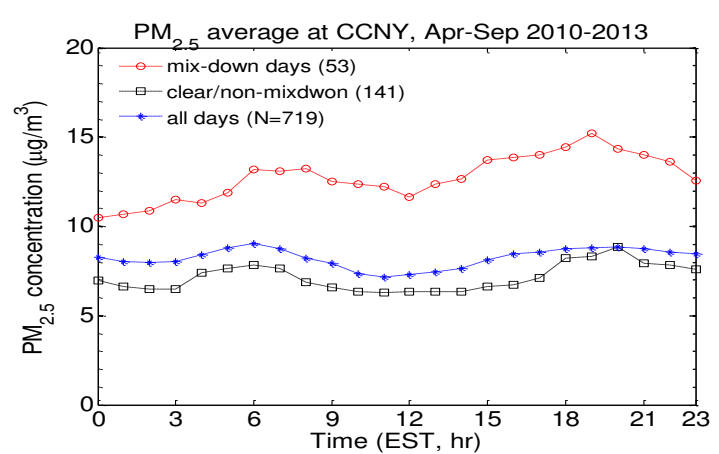

Fig.4 Average $\mathrm{PM}_{2.5}$ on the aloft-plume mixing-down days and clear days.
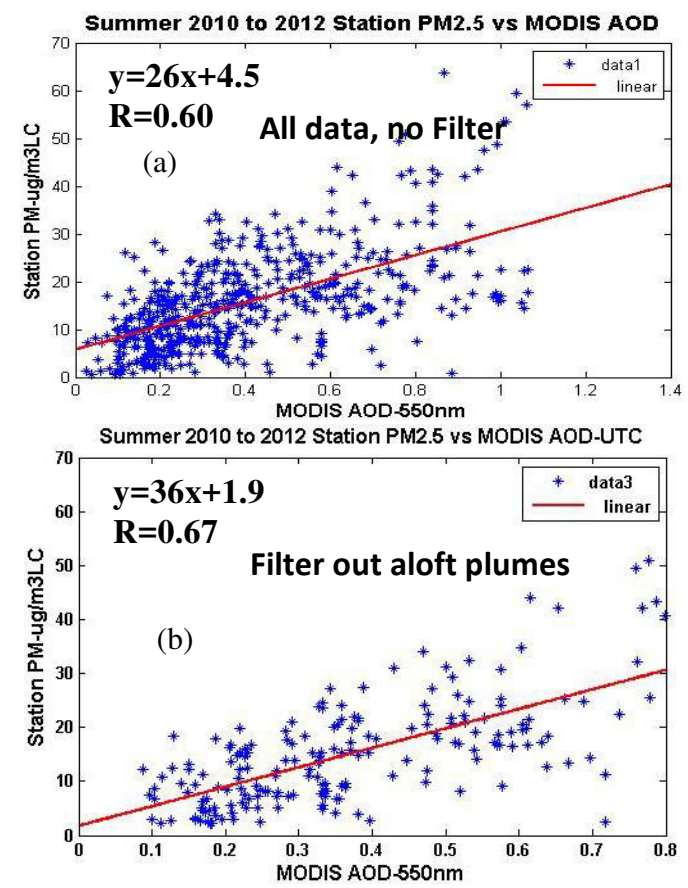

Fig.5. Correlation of MODIS-AOD and $\mathrm{PM}_{2.5}$ in summer, 2010-2012, NYC. (a) All lidar days, (b) lidar days after filtering out aloft-plumes.

\section{SUMMARY}

Extensive aloft-aerosol-plume events and regional transport to the northeastern US are observed with the ground-based multi-wavelength lidar and sunphotometer in New York City. Range-resolved monthly average occurrence of aloft aerosol layers indicates the main transport to occur during March to September which results in the significant enhancement of AOD. Lower Angstrom exponents on the plumes days in April indicate the coarsemode dust aerosol transport while in summer the higher Angstrom exponents indicate the fine-mode aged smoke transport. Meanwhile, the cluster analysis of transport trajectories indicates the primary 6 transport paths at $4-\mathrm{km}$ altitude. Cluster-
2 air-mass transported from the Great Lakes area shows larger AOD and Angstrom exponent while Cluster-6 air-mass traveling from the Pacific Ocean shows the smaller Angstrom exponent and AOD. Other clusters may represent the transport of aged biomass burning aerosols. Additionally, impact of aloft-aerosol-layer on the MODIS column-AOD and ground $\mathrm{PM}_{2.5}$ correlation is demonstrated. Both correlation coefficient and linear slope increase while a reduction in offset occurs when filtering out the aloft aerosol plumes. Finally, we note a significant increase in surface $\mathrm{PM}_{2.5}$ during plume intrusion cases into the PBL which points to mix-down of the aerosols.

ACKNOWLEDGEMENT. This study was supported by National Oceanic and Atmospheric Administration (NOAA) under the CREST Grant \# NA11SEC4810004. Authors greatly appreciate the data from NASA-MODIS and AERONET, EPA, NOAA-HMS and HYSPLIT projects.

\section{REFERENCES}

[1]. Kaufman, Y. J., et al., 2005: The effect of smoke, dust, and pollution aerosol on shallow cloud development over the Atlantic Ocean, Proc. Nat. Acad. Sci., 102, 11207-11212.

[2]. Colarco, P R., et al., 2004: Transport of smoke from Canadian forest fire to the surface near Washington, D.C.: Injection height, entrainment, and optical properties, 2004, J. Geophy. Res., 109, D06203, doi: 10.1029/2003JD004248.

[3]. Engel-Cox, Hoff, R. M., et al., 2006: Integrating lidar and satellite optical depth with ambient monitoring for 3-dimensional particulate characterization. Atmos. Environ. 40, 8056- 8067.

[4]. Hoff, R. M., Christopher, S. A., 2009: Remote sensing of Particulate Pollution from Space: Have we reached the Promised Land, J. Air Waste Manage. Assoc., 59, 645-675.

[5]. Wu, Y., S. Chaw, B. Gross, et al., 2009: Low and optically thin cloud measurements using a RamanMie lidar, Appl. Opt., 48, 1218-1227.

[6]. Holben, B.N., et al., 1998: AERONET A federated instrument network and data archive for aerosol characterization, Rem. Sens. Environ., 66, 116.

[7]. Eck, T. F., B. N. Holben, J. S. Reid, et al., 1999: Wavelength dependence of the optical depth of biomass burning, urban, ad desert dust aerosols, $J$. Geophys. Res., 104, 31333-31349. 